\title{
KINETICS STUDY OF THE DISPROPORTIONATION OF THE IODOUS ACID IN AQUEOUS SULFURIC ACID SOLUTION
}

\author{
Smiljana Marković ${ }^{*}$, Biljana Petrović ${ }^{2}$ \\ ${ }^{1}$ Faculty of Technological Sciences, University of Priština, Kosovska Mitrovica, Serbia. \\ ${ }^{2}$ Faculty of Science, University of Kragujevac, Kragujevac, Serbia.
}

\begin{abstract}
In this paper we reported the kinetics of the disproportionation reaction of iodous acid (HOIO) in aqueous sulfuric acid solutions $\left(0.18 \mathrm{~mol} / \mathrm{dm}^{3}\right)$ studied by spectrophotometrical measurements of the absorbance at suitable wavelength. The changes of the absorbance were caused because the absorbing $I_{2}$ molecule species were generated during the reaction. The disproportionation rate constants are calculated at the temperature range $\mathrm{dm}^{3} \mathrm{~mol}^{-1} \mathrm{~s}^{-1}, \mathrm{k}^{298}=(1.30 \pm 0.07) \mathrm{dm}^{3} \mathrm{~mol}^{-1} \mathrm{~s}^{-1}$ and $\mathrm{k}^{303}$ $=(1.50 \pm 0.10) \mathrm{dm}^{3} \mathrm{~mol}^{-1} \mathrm{~s}^{-1}$, respectively. The corresponding activation energy was determined, for the chosen temperature interval, by a graphical method. In addition, obtained value of activation energy is $E_{a}=38 \pm 5 \mathrm{~kJ} / \mathrm{mol}$. The negative value of Gibbs energy change and other thermodinamical parameters show that is the disproportionation reaction thermodynamically feasible.
\end{abstract} between 285 and $303 \mathrm{~K}$ with average values: $k^{285}=$

$(0.90 \pm 0.08) \mathrm{dm}^{3} \mathrm{~mol}^{-1} \mathrm{~s}^{-1}, \mathrm{k}^{291}=(1.10 \pm 0.10)$

Key words: iodous acid, disproportionation reaction, rate constants, activation energy.

\section{INTRODUCTION}

The homogeneous disproportionation reaction of $\mathrm{HOIO}$ in aqueous solutions of $\mathrm{H}_{2} \mathrm{SO}_{4}$, can be considered as bimolecular chemical reaction:

$$
2 \mathrm{HOIO} \rightarrow \mathrm{IO}_{3}^{-}+2 \mathrm{H}^{+}+\mathrm{HOI}
$$

Namely, the iodous acid simultaneously oxidized to iodate and reduced to hypoiodous acid. According to the published results, this process is proved to be very complex. (Noszticzius et al., 1983), (Lengyel et al., 1996), (Hegedüs et al., 2001). Also, rate constant for the disproportionation reaction was determined in strong acidic water solutions and it was found that the process is slow and autocatalytic (Lengyel et al., 1996).

High acidity of solution, from sulfuric acid addition, is one of the major factor that cause the complexity of the mechanism of studied process.

Because of the high sulfuric acid concentration used in the preparation of HOIO, the experimental conditions for studying the disproportionation are very limited. Reaction mechanism models of this complex system include large number of elementary steps, or those, which can be presented as elementary steps with undetermined reaction rate constants. This is likely cause of lack of compliance between calculated value from the mathematical model data and experimental results. As the consequence, it is rather difficult to obtain reproducible experimental measurement. The limitations in mechanism discussion are referred to the obtained results.

The values of some kinetic parameters, such as reaction rate constant, activation energy and Arrhenius constant were relatively precisely and accurately calculated on the base of limited experimental data. More precisely in the literature are given some data for the rate constant at $298 \mathrm{~K}$. However, data differs from author to author. For example, Noszticzius (Noszticzius et all., 1983) obtained value of the rate constant of $5.4 \mathrm{dm}^{3} \mathrm{~mol}^{-1} \mathrm{~s}^{-1}$ in $\mathrm{H}_{2} \mathrm{SO}_{4}$ concentration range between 0.05 and 0.15 moldm $^{-3}$ at $298 \mathrm{~K}$, while Lengyel (Lengyel et all., 1996) obtained value for the rate constant of $25 \mathrm{dm}^{3} \mathrm{~mol}^{-1} \mathrm{~s}^{-1}$ in the similar experimental conditions at $298 \mathrm{~K}$.

Taking into account that the rate constants are significantly different, we investigated and reported the results for disproportionation reaction and its temperature and acidity dependence under different experimental conditions (Markovic et al., 2002, 2015), (Markovic \& Rakicevic, 2006), (Markovic \& Cekerevac, 2009), (Markovic \& Petrovic, 2010).

In this paper, since our reaction system operates at relatively high acid concentration, we reinvestigated 
the reaction close to our experimental conditions. The Hindmarsh version of the Gear's integrator (Markovic et al., 2002) is used for the numerical simulation.

Otherwise, experimental relevant data for the kinetics of iodous acid disproportionation, based on the values obtained in our experiments and data obtained in our numerical calculations, are compared with results obtained in some other investigations found in literature.

\section{EXPERIMENTAL}

The experiments are performed in a similar way as described in our previous papers (Markovic et al., 2002), (Markovic \& Petrovic, 2010) where the process is studied at isothermal conditions.

Experimental solution is prepared with double distilled water with conductivity meter tested purity. The stock solutions are prepared using pro analysis chemicals produced by "Merck".

To obtain HOIO, it is necessary to prepare the solution that contains intermediary species $\mathrm{I}^{3+}$. The mixture of iodine (I) iodine (III) species reaction solution is prepared by dissolving $\mathrm{I}_{2}$ and $\mathrm{KJO}_{3}$ (in relation 1:5) in concentrated sulfuric acid (96\%) (Noszticzius et al., 1983). Species $\mathrm{I}^{3+}$ are stable exclusively in the presence of iodate added in excess. The role of excess of iodate is to prevent formation of $\mathrm{I}^{+}$. In this case complex reaction proceeds, which can be described by stoichiometry of the chemical reaction:

$$
\mathrm{I}_{2}+3 \mathrm{IO}_{3}^{-}+8 \mathrm{H}^{+} \rightarrow 5 \mathrm{IO}^{+}+4 \mathrm{H}_{2} \mathrm{O}
$$

Obtained $\mathrm{IO}^{+}$ion, formulated as liquid iodosile sulfate $(\mathrm{IO})_{2} \mathrm{SO}_{4}$, quickly decomposes in water solution of $\mathrm{H}_{2} \mathrm{SO}_{4}$ and than $\mathrm{I}^{3+}$ is presented in the form of iodous acid HOIO:

$$
\mathrm{IO}^{+}+\mathrm{H}_{2} \mathrm{O} \rightarrow \mathrm{H}_{2} \mathrm{IO}^{+} \rightarrow \mathrm{H}^{+}+\mathrm{HIO}_{2}
$$

The spectrophotometer measurements of the absorbance changes at $469 \mathrm{~nm}$ (absorbance maximum), corresponding to absorption by the $\mathrm{I}_{2}$ molecule species, is indirectly monitored by the UV-v is spectroscopic method in $10-\mathrm{mm}$ quartz cuvettes. The temperatures of the reaction mixtures were maintained constant with an accuracy of $\pm 0.2^{\circ} \mathrm{C}$ by circulating water from a thermostatic bath.

The fresh solutions for experiments are prepared by dilution of stock solution of reactants before every new series of measurements to obtain reproducible results. The prepared solutions are kept in dark vessels and experiments are performed in semidarkness conditions and absence of direct overhead lights.

\section{RESULTS AND DISCUSSION}

The disproportionation reaction of iodous acid (HOIO) was studied at different experimental conditions by different experimental method. According to the previously published results, (Noszticzius et al., 1983), (Lengyel et al., 1996) the values of the obtained rate constants for disproportionation reaction are very different. Results evaluated from our spectrophotometric measurements in temperature range from $285-303 \mathrm{~K}$ enable the calculation of the rate constants for the reaction of disproportionation of HOIO. All values are given in Table 1

The light absorbance is caused exclusively by $\mathrm{I}_{2}$ molecule absorption (Awtrey \& Connik, 1951).

The increase of the concentration of originated $\mathrm{I}_{2}$ during the reaction was followed at $469 \mathrm{~nm}$ (absorbance maximum). The other part on the spectrum was unchanged during the reaction. The molar absorption coefficient value for $I_{2}$ is determined from the calibration diagram and it is equal to $\varepsilon=746$ $\mathrm{m}^{2} \mathrm{~mol}^{-1}$.

Determination of the concentration other relevant species, such as $\mathrm{H}^{+}, \mathrm{H}_{2} \mathrm{IO}^{+}$, and $\mathrm{IO}_{3}{ }^{-}$in the $\mathrm{pH}$ range between 1 and 2 , formed during the disproportionation reaction, was discussed in detail in the paper (Markovic et al., 2015).

The reactions were followed under the different initial concentration of reactant (for the iodous acid from $1.00 \times 10^{-4}$ to $1.40 \times 10^{-4}$ moldm $^{-3}$ and iodate from $1.00 \times 10^{-4}$ to $4.80 \times 10^{-4}$ moldm $^{-3}$ ) at different values temperature $(285,291,298$ and $303 \mathrm{~K})$ with constant solution acidity $\left(0.18\right.$ moldm $\left.^{-3} \mathrm{H}_{2} \mathrm{SO}_{4}\right)$.

The numerical simulation of obtained experimental data was performed in a manner similar to one described in previous paper (Markovic et al., 2002). The method consists of converting the chemical reactions by equations (denoted by $(\mathrm{R} 1)$ to $(\mathrm{R} 4)$ for direct reactions and ( $\mathrm{R}-1)$ to $(\mathrm{R}-4)$ for a reverse reactions) given mechanism in the model. Accepting a model of the mechanism and using the experimentally measured value for the rate constants, could be carried out successful simulation. 
Table 1. Rate constants for the disproportionation reaction of HOIO calculated in the temperature range from 285 to $303 \mathrm{~K}$ by measuring the increasing $\mathrm{I}_{2}$ molecule specie absorption at $469 \mathrm{~nm}$.

\begin{tabular}{|c|c|c|c|c|c|}
\hline $\begin{array}{c}\mathrm{T} \\
(\mathrm{K})\end{array}$ & $\begin{array}{c}{[\mathrm{HOIO}]} \\
\left(\mathrm{moldm}^{-3}\right) \times 10^{4}\end{array}$ & $\begin{array}{c}{\left[\mathrm{IO}_{3}^{-}\right]} \\
\left(\text {moldm }^{3}\right) \times 10^{4}\end{array}$ & $\begin{array}{c}{\left[\mathrm{H}_{2} \mathrm{SO}_{4}\right]} \\
\left(\mathrm{mol} / \mathrm{dm}^{3}\right)\end{array}$ & $\begin{array}{c}\mathrm{k} \\
\left(\mathrm{dm}^{3} \mathrm{~mol}^{-1} \mathrm{~s}^{-1}\right)\end{array}$ & $\begin{array}{c}\mathrm{k}_{\mathrm{av}} \\
\left(\mathrm{dm}^{3} \mathrm{~mol}^{-1} \mathrm{~s}^{-1}\right)\end{array}$ \\
\hline \multirow[t]{6}{*}{285} & 1.00 & 3.23 & 0.18 & 0.98 & \multirow{6}{*}{$0.90 \pm 0.08$} \\
\hline & 1.10 & 3.23 & & 0.96 & \\
\hline & 1.20 & 3.23 & & 0.87 & \\
\hline & 1.00 & 4.80 & & 0.83 & \\
\hline & 1.30 & 4.80 & & 0.92 & \\
\hline & 1.40 & 4.80 & & 0.82 & \\
\hline \multirow[t]{6}{*}{291} & 1.20 & 4.80 & 0.18 & 1.20 & \multirow{6}{*}{$1.10 \pm 0.10$} \\
\hline & 1.00 & 3.23 & & 1.13 & \\
\hline & 1.00 & 4.80 & & 1.10 & \\
\hline & 1.30 & 4.80 & & 1.02 & \\
\hline & 1.30 & 3.23 & & 1.06 & \\
\hline & 1.40 & 4.80 & & 1.03 & \\
\hline \multirow[t]{6}{*}{298} & 1.00 & 3.23 & 0.18 & 1.25 & \multirow{6}{*}{$1.30 \pm 0.07$} \\
\hline & 1.20 & 4.80 & & 1.33 & \\
\hline & 1.10 & 3.23 & & 1.30 & \\
\hline & 1.30 & 4.80 & & 1.32 & \\
\hline & 1.40 & 4.80 & & 1.37 & \\
\hline & 1.10 & 1.00 & & 1.26 & \\
\hline \multirow[t]{6}{*}{303} & 1.00 & 3.23 & 0.18 & 1.33 & \multirow{6}{*}{$1.50 \pm 0.10$} \\
\hline & 1.10 & 3.23 & & 1.53 & \\
\hline & 1.00 & 4.80 & & 1.40 & \\
\hline & 1.30 & 3.23 & & 1.50 & \\
\hline & 1.20 & 4.80 & & 1.56 & \\
\hline & 1.40 & 4.80 & & 1.60 & \\
\hline
\end{tabular}

Due to the numerical simulation of the experimental absorbance, values are converted into concentration using the Lambert-Beer's Law (equation $\mathcal{A}=\xi \cdot l \cdot c)$.

The kinetic of the disproportionation process was sensitive to both $\mathrm{k}_{(\mathrm{Eq} .1)}$ and $\mathrm{k}_{(\mathrm{Eq} .2)}$, so the rate low could be represent by equations (1) and (2):

$$
\begin{gathered}
d[\mathrm{HOIO}] / d t=k_{(E q . \mathrm{l})}[\mathrm{HOIO}]^{2} \\
d[\mathrm{HOIO}] / d t=k_{(E q .2)}[\mathrm{HOIO}][\mathrm{HOI}]
\end{gathered}
$$

The rate constant determination for reaction between HOIO and HOI does not significantly affect to the other reactions and could be neglected, probably because of the very narrow limit of feasible experimental conditions.

Following experimental data, the mechanism of disproportionation reaction of iodous acid is discussed. The assumed mechanism of the reaction of iodous acid includes sequence of reactions, comprising the step of the intermediary species HOI generation, which is presented as follows.

In the first step HOIO disproportionate to iodate and intermediate $\mathrm{HOI}$ :

$$
2 \mathrm{HOIO} \rightarrow \mathrm{IO}_{3}^{-}+\mathrm{H}^{+}+\mathrm{HOI}
$$

The intermediate species HOI relatively rapidly reacts with $\mathrm{HOIO}$ generating another intermediary iodide ion $\mathrm{I}^{-}$:

$$
\mathrm{HOI}+\mathrm{HOIO} \rightarrow \mathrm{IO}_{3}^{-}+2 \mathrm{H}^{+}+\mathrm{I}
$$

The last intermediate $\mathrm{I}^{-}$reacts very fast with $\mathrm{HOIO}$ forming $\mathrm{HOI}$ and also with $\mathrm{HOI}$ forming $\mathrm{I}_{2}$ :

$$
\begin{aligned}
& \mathrm{HOIO}+\mathrm{I}+\mathrm{H}^{+} \leftrightarrow 2 \mathrm{HOI} \\
& \mathrm{HOI}+\mathrm{I}+\mathrm{H}^{+} \leftrightarrow \mathrm{I}_{2}+\mathrm{H}_{2} \mathrm{O}
\end{aligned}
$$

The reverse reactions of (R3) and (R4) have not a significant role in the kinetics under consideration. Therefore, the overall stoichiometry of the disproportionation reaction is:

$$
5 \mathrm{HOIO}=\mathrm{I}_{2}+3 \mathrm{IO}_{3}^{-}+\mathrm{H}_{2} \mathrm{O}+3 \mathrm{H}^{+}
$$

However, the process of disproportionation is very complex and only iodine could be tracked continually by spectrophotometer. The reactions (R3) and (R4) are very fast. Consequently, the kinetic are sensitive only to reactions (R1) and (R2).

Although the reverse reactions of iodine hydrolysis are present in disproportionation and they do not have a significant role in the kinetics.

In our experiments, the complete reaction of $\mathrm{I}_{2}$ forming is much faster than obtained in the former

\section{Chemistry}


experiments with $\mathrm{Hg}^{2+}$, were disproportionation of HOIO was studied in similar experimental conditions (Markovic et al., 2002), (Markovic \& Rakicevic, 2006), (Markovic \& Cekerevac, 2009), (Markovic \& Petrovic, 2010). From these reasons experiments must be performed very precise and carefully.

Also, the reactions were followed for 10 to 15 minutes, while disproportionation reactions in the presence of excess of $\mathrm{Hg}^{2+}$ ions were studied several hours. It is obvious that disproportionation reaction and the intermediary reactions of iodine formations in absence of $\mathrm{Hg}^{2+}$ ions are notably faster and might be autocatalytic, what is in agreement with previous observations (Noszticzius et al., 1983), (Lengyel et al., 1996). The comparison of both experimental and calculated values with literature data supports our opinion.

The rate constants increase with temperature, but they are somehow different from those cited in literature. The effect of sulfuric acid and temperature is probably one of the main reasons for the different values of the rate constants of disproportionation reaction. Although some of them have the same order of magnitude. In paper (Markovic et al., 2002) we found that their values are approximately one-half of those obtained by Noszticzius. Comparing our values with values reported in the literature by Lengyel (Lengyel et al., 1996) can be concluded that we obtained 15 times lower rate constant and approximately 1.5 times lower than the values obtained when the $\mathrm{Hg}^{2+}$-ion was in excess (Markovic et al., 2002).

The value of the activation energy was determined graphically for the temperature interval from 285 to $303 \mathrm{~K}$, using the Arrhenius relation presented by eq.(3):

$$
k=A \exp \left(-E_{a} / R T\right)
$$

$\mathrm{A}$ is a constant, $\mathrm{E}_{\mathrm{a}}$ is the activation energy and $\mathrm{T}$ is the thermodynamic temperature. Average activation energy of $38 \pm 5 \mathrm{kJmol}^{-1}$ is determined graphically as the slope of straight line from the lnk $=f(1 / T)$ dependencies. In the Fig 1 is present the linear form of the Arrhenius equation.

The intercept of the Arrhenius plot with the ordinate gives a pre-exponential factor which is $\mathrm{A}=2 \times 10^{9} \mathrm{dm}^{3} \mathrm{~mol}^{-1} \mathrm{~s}^{-1}$.

Activation energy value is relatively low comparing with previously found (Markovic et al., 2002) and it confirm the presence of the catalytic impacts in the disproportionation process (Markovic \& Cekerevac, 2009), (Főrsterling \& Varga, 1993), (Hegedüs et al., 2001). There were found that the presence of sulfuric acid increases the rate of the observed reaction; it was assumed that its impact is significant in an overall catalytic mechanism of the process, (Markovic \& Petrovic, 2010).

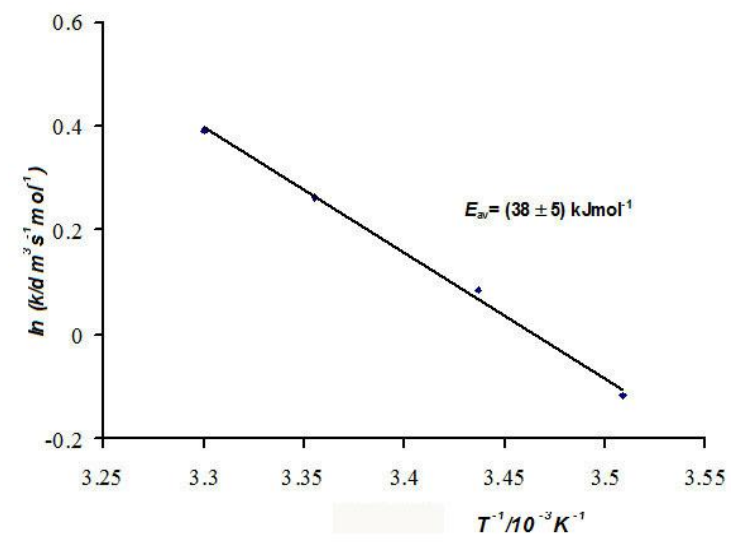

Fig. 1 The Arrhenius equation dependence of $\operatorname{lnk} v s$. $1 / \mathrm{T}$.

On the base of the date obtained in the corresponding temperature interval other thermodynamic parameters are also calculated: $\Delta \mathrm{H}=$ $(-17 \pm 1) \mathrm{kJmol}^{-1}, \Delta \mathrm{S}=(199 \pm 3) \mathrm{JK}^{-1} \mathrm{~mol}^{-1}, \Delta \mathrm{G}=$ $(-42 \pm 3) \mathrm{kJmol}^{-1}$.

The negative values of Gibbs energy of reaction (1), the overall reactions (R5) for disproportionation of HOIO shows thermodynamically possibility for given values of the initial concentration of reactants and the temperature in studied system.

The ionic strength of the studied solutions usually does not affect on the rate of the process until the disproportionation of the neutral molecule HOIO occurred. Although its impact is likely in the area in which they appear intermediate ionic species. Therefore, in this case is not taken into consideration.

\section{CONCLUSION}

On the base of series of spectrophotometer measurements of the absorbance change of $\mathrm{I}_{2}$ molecule species at $469 \mathrm{~nm}$, generated during the chemical reaction, the rate for the disproportionation of $\mathrm{HOIO}$ in the temperature range between 285 and $303 \mathrm{~K}$ have been calculated. The observed rate constants varied between $\mathrm{k}^{285}=(0.90 \pm 0.08) \mathrm{dm}^{3} \mathrm{~mol}^{-1} \mathrm{~s}^{-1}$ and $\mathrm{k}^{303}=$ $(1.5 \pm 0.1) \mathrm{dm}^{3} \mathrm{~mol}^{-1} \mathrm{~s}^{-1}$, respectively, depending of the temperature. In the given temperature interval the disproportionation rate of HOIO increases about 1.6 times.

\section{Chemistry}


Value of activation energy of $38 \pm 5 \mathrm{kJmol}^{-1}$ was determined graphically for the chosen temperature interval. Subsequently, the Arrhenius constant was calculated $\left(2 \times 10^{9} \mathrm{dm}^{3} \mathrm{~mol}^{-1} \mathrm{~s}^{-1}\right)$ as well.

The kinetics of disproportionation of HOIO and its thermodynamic parameters, the negative values of Gibbs energy in the investigated temperature range, show that the process is thermodynamically possible.

\section{REFERENCES}

Awtrey, A. D., \& Connik, R. E. J., 1951. The Absorption Spectra of $\mathrm{I}_{2}, \mathrm{I}_{3}{ }^{-}, \mathrm{I}^{-}, \mathrm{IO}_{3}{ }^{-}, \mathrm{S}_{4} \mathrm{O}_{6}{ }^{\circ}$ and $\mathrm{S}_{2} \mathrm{O}_{3}{ }^{2}$. Heat of the Reaction $\mathrm{I}_{3}{ }^{-}=\mathrm{I}_{2}+\mathrm{I}^{-}$, Journal of the American Chemical Society, 73 (4) pp.18421843.

Főrsterling, H. D., \& Varga, M., 1993. Bromous acid/cerium (4+): reaction and $\mathrm{HBrO}_{2}$ disproportionation measured in sulfuric acid solution at different acidites, The Journal of Physical Chemistry, 97 (30), pp. 7932-7938-524.

Hegedüs, L., Wittman, M., Noszticzius, Z., Yan, S., Sirimungkala, A., Főrsterling, H. D., \& Field, R. J. 2001. HPLC analysis of complete BZ systems, Evolution of the chemical composition in cerium and ferroin catalysed batch oscillators: experiments and model calculations, Faraday Discussions, (120) 2138, pp. 85-104.

Lengyel, I., Li, J., Kustin, K., \& Epstein, I. R., 1996. Rate constants for reactions between iodine and chlorine-containing species: a detailed mechanism of chlorine dioxside/chlorite-iodite reaction, Journal of the American Chemical Society, 118 (15), pp. 37083719.

Marković, S., Rakicević, N., \& Mišljenović, Đ., 2002. The temperature dependence of the

\footnotetext{
*E-mail: markovicsmiljana@gmail.com
}

disproportionation reaction of iodous acid in aqueous sulfuric acid solutions, Journal of the Serbian Chemical Society, 67(5) pp. 347-351, DOI: 10298/JSCO205347M.

Marković, S., \& Rakićević, N., 2006. Determination of the rate of iodous acid disproportionation in aqueous sulfuric acid solution, Reaction Kinetics and Catalysis Leters, 89 (1) pp. 3-8, DOI: 10.107/S1140.06-0.080-9.

Marković, S., \& Cekerevac, M., 2009. The rate of the disproportionation of iodous acidity at diferent acidity values in aqueous sulfuric acid solution, Reaction Kinetics and Catalysis Leters, 97 pp. 1318, DOI: 10.107/S114-0.09-0.03-7.

Marković, S., \& Petrović, B., 2010. Kinetics of the disproportionation reaction $\mathrm{HIO}_{2}$ in aqueous acid solutions, International Journal of Chemical Kinetics Inter, 42 pp. 687-691, DOI: 10.102 /kin20516.

Marković, S., Karkalić, R., \& Petrović, B., 2015. Disproportionation reaction of iodous acid, HOIO. Determination of the concentrations of the relevant ionic species $\mathrm{H}^{+}, \mathrm{H}_{2} \mathrm{OI}^{+}$, and $\mathrm{IO}^{3-}$, Research on Chemical Intermediates, 41 (3) pp. 1293-1330, DOI: 10.107/s164-0.1273-2.

Noszticzius, Z., Noszticzius, E., \& Schelly, Z. A., 1983. Use of ion selective electrodes for monitoring oscillating reactions, 2. Potential response of bromide-iodide selective electrodes in slow corrosive processes, Disproportionation of bromous and iodous acids. A Lotka-Voltera model for the halate oscillators, The Journal of Physical Chemistry, 87 (3), pp. 510-524. 